\title{
Body mass index status and accuracy of individual weight status perception among college going students in South India
}

\section{Saiprasanna Narasimmal, Ilavenil Karunakaran*, Sasikumar Shanmugam, K. Subashini, S. D. Nalinakumari}

Department of Anatomy, Chennai Medical College Hospital and Research Centre, Irungalur, Trichy, TamilNadu, India

Received: 14 April 2016

Accepted: 07 May 2016

\section{*Correspondence:}

Dr. Karunakaran Ilavenil,

E-mail: ilavenil.k@gmail.com

Copyright: (C) the author(s), publisher and licensee Medip Academy. This is an open-access article distributed under the terms of the Creative Commons Attribution Non-Commercial License, which permits unrestricted non-commercial use, distribution, and reproduction in any medium, provided the original work is properly cited.

\section{ABSTRACT}

Background: India faces the burgeoning twin problems of underweight and obesity. Accurate weight perception is vital to the institution and practice of weight management behaviour. The study aims at determining the BMI status of college students in South India and evaluating the accuracy of their weight status perception.

Methods: A cross sectional observational study was carried out on a sample of 500 college students. Data regarding height, weight and body weight perception was obtained by structured questionnaire. Anthropometric measurements were recorded. The BMI calculated was used to categorize the BMI pattern of individuals according to WHO criteria for Asian Indians. This was correlated with self-perceived BMI to evaluate accuracy. All data were analysed by Statistical Package for the Social Sciences (SPSS) software.

Results: $21.2 \%$ of the samples were underweight, $23.4 \%$ were overweight and $9.6 \%$ were obese. There was a statistically significant correlation between the self-reported BMI and actual BMI as assessed by Pearson correlation $(\mathrm{r}=.884, \mathrm{p}<.001$, two-tailed). 62\% accurately perceived weight status. Agreement of perceived and measured BMI was found to be moderate among underweight and overweight groups. Agreement between perceived and measured normal BMI was found to be fair as determined by Kappa characteristic.

Conclusions: Our study validates the current view that underweight and overweight continue to thrive concomitantly in urban Indian centers among youngsters of college-going age group. Perception of body weight is more accurate among underweight and overweight groups as compared to normal students, though overall accuracy was $62 \%$.

Keywords: BMI status, Perception, Accuracy, Underweight, Overweight, Obesity, College students

\section{INTRODUCTION}

Developing countries like India are witnessing a concurrent rise of both obesity and malnutrition. ${ }^{1}$ Accurate self- estimation of body weight and body image may be crucial in inducing optimal weight maintenance behaviour. $^{2}$

Reports on agreement between perceived weight and measured body weight by adolescents and young adults vary. $^{3-7}$ Most studies on obesity are from the developed countries. There are very few Indian studies that deal with the young adult age group of 18-22 years.

We designed this study to collect data regarding BMI patterns according to the Indian BMI cut-off values among college students in Tamil nadu and to ascertain whether body weight perceptions of the students matched actual BMI. 


\section{METHODS}

\section{A cross-sectional observational study was carried out on students of engineering and medical}

Colleges in an urban city located in Tamil Nadu in Southern India. A convenience sample of 500 students, both male and female students, between the ages of 18 to 22 years volunteered for the study. All participants were Indian by ethnicity. Participants who suffered from hormonal disorders, chronic illnesses and those who were under chronic medication were excluded from the study. Institutional Ethical Committee (IEC) Clearance was obtained prior to the conduction of Study. Informed consent was obtained from the study participants.

\section{Data collection}

Participants were asked to fill a structured questionnaire after a brief introduction by the investigators. The questionnaire comprised of five sections eliciting social and demographic data, details of body weight perception and reported height and weight, dietary patterns and habits, physical activity patterns and medical history that included menstrual history from female participants. The questionnaire was modified from those used in previous studies that evaluated similar criteria and used questions that have been validated and proven to accurately assess the factors under study. ${ }^{9,10}$ The questionnaire was pretested and validated on a group of 20 subjects before administration, who were not part of the study sample. Investigators were present throughout the duration of questionnaire administration, in order to clarify any doubts that were raised. Body weight perceptions were categorized as below normal, normal and above normal.

\section{Anthropometric measurements}

Anthropometric measurements were recorded by trained personnel immediately on the same day after the administration and collection of questionnaire. Weight and height were measured by standardized weighing scale and stadiometer respectively. Two recordings were made for each measure and the mean taken for entry into the data entry proforma that was used for calculation of Body Mass Index (BMI). All readings were taken with light clothing and without shoes. The measured BMI was calculated as the measured weight in kilograms by measured height in meters square $\left(\mathrm{kg} / \mathrm{m}^{2}\right)$. The revised guideline action-point cut-off values for defining overweight and obesity as suggested by $\mathrm{WHO}^{8}$ were used to categorize participants by $\mathrm{BMI}$. $\mathrm{BMI}<18.4$ is underweight, between 18.5 to 22.9 is considered normal, 23 to 27.5 is overweight and greater than 27.5 is considered obese.

Hip and waist circumference was measured by flexible measuring tape in inches. Measurements of waist were taken at the level of the umbilicus and the hip at the level of maximum circumference of the buttocks. Waist to Hip ratio was calculated as circumference of waist divided by the circumference of the Hip. Presence of abdominal obesity was determined by the following values $>0.90$ for men and $>0.80$ for women as per guidelines for Asian Indians. ${ }^{11}$

\section{Statistical analysis}

All data were analysed using the software Statistical Package for the Social Sciences.

(Windows version 16.0; SPSS Inc.,). All numerical values were expressed as mean $\pm \mathrm{SD}$. The prevalence of overweight obesity and abdominal obesity was calculated and expressed as percentages. The agreement between reported BMI and measured BMI in each of the three groups, i.e., underweight, normal and overweight was evaluated by Pearson correlation and the concordance between weight perception and measured BMI category was calculated by Kappa statistics.

\section{RESULTS}

\section{Sample characteristics}

The sample comprised of 500 students $(n=500)$ between the ages of $18-22$ years of whom 222 were $(44 \%)$ male and $278(56 \%)$ were female.

BMI status: Prevalence of overweight and obesity (Figures 1-3.)

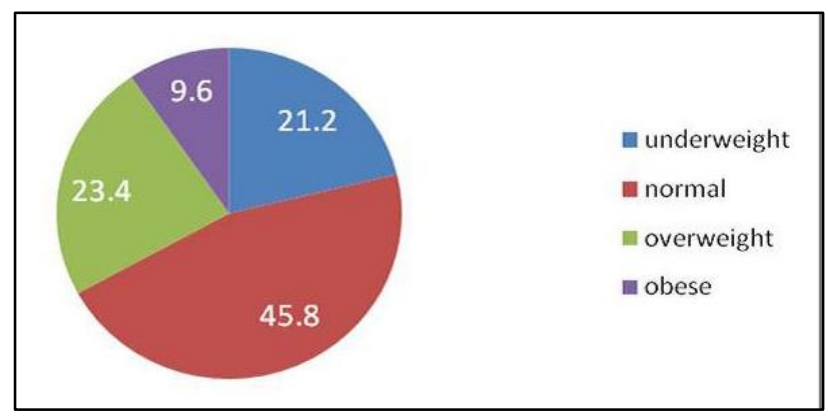

Figure 1: Percentage prevalence of underweight, normal, overweight and obesity among study group.

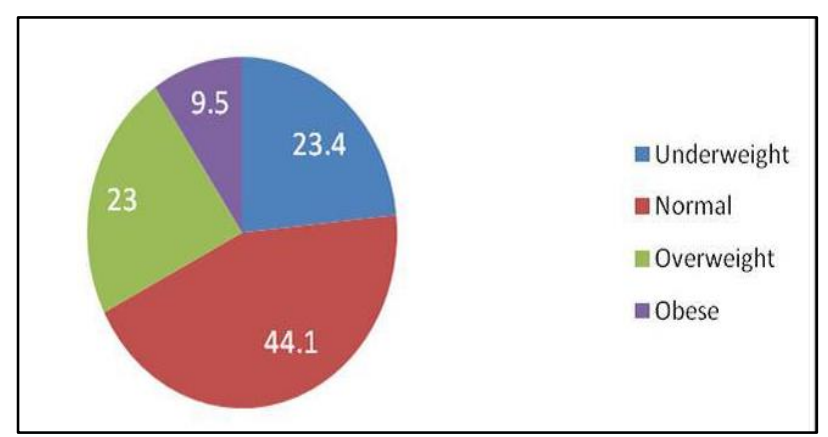

Figure 2: Percentage prevalence of underweight, normal, overweight and obesity among males. 
Based on anthropometric measures of height and weight on a sample of 500, actual or measured BMI was calculated. According to the Asian -Indian guidelines for weight categorization, $21.2 \%(n=106)$ were underweight, $45.8 \% \quad(n=229)$ were normal, $23.4 \% \quad(n=117)$ were overweight and $9.6 \%(n=48)$ were obese.

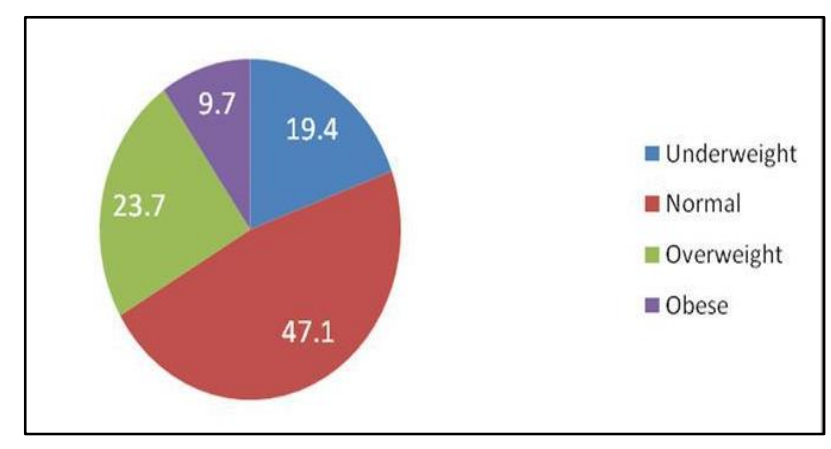

Figure 3: Percentage prevalence of underweight, normal, overweight and obesity among females.

Among the males $(n=222), 23.4 \% \quad(n=52)$ were underweight, 44.1\%( $n=98)$ were normal, $23 \%(n=51)$ were overweight and $9.5 \%(n=21)$ were obese. Among the females, $19.4 \%(n=54)$ were underweight, $47.1 \%$ $(\mathrm{n}=131)$ were normal, $23.7 \%(\mathrm{n}=66)$ were overweight and $9.7 \%(n=27)$ were obese.

\section{Waist-hip ratio (WHR)}

WHR was abnormal in $12.2 \%$ of males and in $16.6 \%$ of females.

\section{Association of self-reported BMI to actual BMI}

\section{Reported BMI}

Out of 500 respondents, only 180 reported height and weight. The reported BMI was calculated using the reported values. Based on reported BMI values, $17.8 \%$ $(n=32)$ felt they were underweight, $53.9 \%(n=97)$ were normal, $12.8 \%(n=23)$ were overweight and $15.6 \%(n=$ 28) were obese. Among 44 male students who had reported height and weight, reported BMI was calculated, based on which $34 \%(n=15)$ felt they were underweight, $45.5 \%(n=20)$ were normal, $6.8 \%(n=3)$ were overweight and $13.6 \%(n=6)$ were obese. Among 136 female students who had reported height and weight, reported BMI was calculated, based on which $12.5 \% \quad(\mathrm{n}=17)$ were underweight, $56.6 \%(n=77)$ were normal, $14.7 \%(n=20)$ were overweight and $16.2 \%(n=22)$ were obese.

The association between the self-reported BMI and actual BMI was assessed by Pearson correlation. There was a statistically significant correlation between the two variables among the entire respondents $(n=180)(r=.884$, $\mathrm{p}<.001$, two-tailed). Among male respondents $(\mathrm{n}=44)$, the correlation between reported BMI and actual BMI was found to be statistically significant. $(r=.952, p<0.001$, two-tailed). Among female respondents also $(n=136)$, the correlation between reported BMI and actual BMI was found to be statistically significant $(r=.846, p<.001$, twotailed).

\section{Perceived weight}

Among the total students, 469 students had responded to the questions on body weight perception. $25.8 \%(\mathrm{n}=121)$ thought they were underweight, 39.7\% $(n=186)$ thought they were of normal weight and $34.5 \%(n=162)$ perceived themselves as overweight/obese.

Among the males $(n=209), 34.5 \%(n=72)$ felt they were underweight, $38.3 \% \quad(\mathrm{n}=80)$ perceived themselves as normal, $27.3 \% \quad(n=57)$ thought they were overweight/obese. Among the females $(n=260), 18.8 \%$ $(n=49)$ felt they were underweight, $40.8 \% \quad(n=106)$ perceived themselves as normal, $40.4 \%(n=105)$ thought they were overweight/obese.

\section{Association of perceived weight status with actual BMI (Figure 4)}

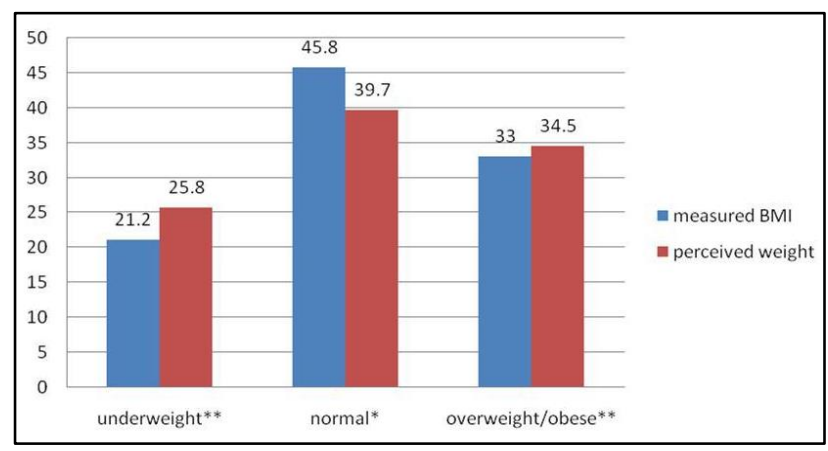

** Moderate agreement;* Fair agreement.

Figure 4: Relative percentages of measured BMI to perceived weight status.

Among the participants, $62 \%$ accurately perceived weight status. $54 \%$ and $67 \%$ were correct in their weight perception among males and females respectively. Agreement between the perceived weight was determined by kappa statistic. The kappa value for perceived underweight and measured underweight was $0.475 \pm$ 0.047 , which is interpreted to be in moderate agreement. The calculated kappa value among the perceived and measured normal category was $0.300 \pm .0044$ with an interpretation of fair. In the overweight/obese category kappa was $0.591 \pm 0.047$, an interpretation of moderate agreement.

\section{DISCUSSION}

\section{Weight status among college students}

The study showed an almost equal prevalence of underweight and overweight. Reported rates are 
consistent with increasing overweight rates in urban India and among young adults.

Very few studies have been performed to measure prevalence of obesity among Indian college students (between the ages of 18-22) and of those that have been done, many have used international BMI cut-off values for classification of weight categories. The definition of weight categories in this study follows the WHO modified values for Asian Indians. ${ }^{8}$

Our study results show that $21.2 \%$ of students were underweight, $45.8 \%$ were normal, $23.4 \%$ were overweight and $9.6 \%$ were obese. A study on similar age groups in Malaysia show prevalence patterns of underweight as $16.7 \%$, normal of $44.6 \%$, overweight of $14.6 \%$, pre-obesity of $17.3 \%$ and obesity of $6.5 \%$ among the Indian students. ${ }^{12}$ This shows similar patterns as in our study, with minor differences, probably due to the definition and use of pre-obese category from BMI of 25$29.9 \mathrm{~kg} / \mathrm{m}^{2}$ whereas our study included the range of BMI from 23-27.5 as overweight. A study among South Indian college students reports $21 \%$ overweight and $3 \%$ obesity, but the calculated BMI is based on reported height and weight and data on accuracy of weight perception is not available. ${ }^{13}$ A study in Bengal reported the prevalence of overweight in males as $10.9 \%$ and in females as $27.5 \%$. There were no obese men and only $0.7 \%$ of the women were obese. ${ }^{14}$ The lower values of obesity in the study can be explained by the fact that the authors used international cut-off values in categorizing BMI which has been show to underrate the presence of overweight and obesity in Asian-Indians.

Among the males, $23.4 \%$ were underweight, $44.1 \%$ were normal, $23 \%$ were overweight and $9.5 \%$ were obese. Among the females, $19.4 \%$ were underweight, $47.1 \%$ were normal, $23.7 \%$ were overweight and $9.7 \%$ were obese. Studies on female college students report underweight, overweight and obesity rates of $31.5,18.5$ and 4.5 respectively, and rates of $17,75.5$ and 7.5 . $^{7,15}$ Our prevalence rates show that prevalence of underweight is almost equal to the prevalence of overweight. The urban setting of the study might reflect the access to processed, high calorie foods and better means of both private and public transport and automation of devices that could in turn, lead to the increase in overweight and obesity prevalence on par with that of underweight. The increased rates of overweight seen in young adults are in concurrence with the trends of increasing obesity and overweight in urban children and adolescents and in urban men and women. ${ }^{16,17}$

Despite $32.5 \%$ of males falling into the overweight/obese category, WHR was abnormal in only $12.2 \%$; and despite $33.4 \%$ of females falling into the overweight/obese category, WHR was abnormal in only $16.6 \%$. WHR increases with age and hence, the reason for this disparity could lie in the relative youth of the sample population.

\section{Association of perceived BMI with measured BMI}

Significant correlation existed between reported BMI and actual BMI. Perceived BMI and actual BMI show moderate agreement among underweight and overweight groups and fair agreement among the normal group (kappa statistic). Agreement of perceived BMI with actual BMI was done in two ways. The first was a comparison of BMI calculated from measured height and weight with that calculated from self- reported height and weight. The correlation of the two values $(n=180)$ was significant $r=.884, p<.001$, two-tailed as calculated by Pearson correlation. Brener et al compared actual BMI with BMI calculated from reported height and weight and found more than $20 \%$ weight misperception. ${ }^{2}$ In our sample, only 180 students out of 500 were aware of height and weight. The perception of weight status in these students correlated well with measured BMI. Possibly the increased awareness levels on knowing height and weight influences their perception of weight status. Studies are needed to further investigate whether the very act of knowing height and weight is associated with better perception of body weight status. ${ }^{18}$

The second method was to compare measured BMI with self-perception of students as below normal (underweight), normal and above normal (overweight) categories. Agreement of self- perceived weight with measured weight was found to be moderate in the underweight and overweight category (Kappa 0.475 and .591 respectively) and fair in the normal category (Kappa .300). A study on African-American college age males showed that $59.7 \%$ of overweight/obese males misperceived their weight status. ${ }^{18}$

$62 \%$ accurately perceived weight status and $38 \%$ of students misperceived their weight status in our study. A study on weight perception accuracy on female university students in Poland shows that $71.9 \%$ of students accurately estimated their weight with $28.1 \%$ misperceiving actual weight status. ${ }^{19}$ A similar study on female college students in Karachi showed that $66.27 \%$ of the students accurately perceived body weight status while $33.73 \%$ misperceived it. ${ }^{4}$ Our study results bear a resemblance to the above reported studies showing a moderate agreement and $38 \%$ misperception of weight status. The study results differ from those that report higher agreement, and higher misperception. ${ }^{3,20}$

According to our study results, $54 \%$ of males and $67 \%$ of females were correct in their weight perception. This differs from studies which often show more accurate weight perception among males as compared to females. $^{2,20}$

\section{CONCLUSION}

The measured prevalence rates of overweight and obesity corresponds to the current trends of increasing overweight rates in urban centers of developing countries 
and among young adults. There is fairly accurate perception of weight status among the study population and the amount of misperception was lesser among students who were aware of their height and weight measures. Underweight and overweight students showed better perception scores as compared to normal students. The awareness of weight status among college students warrants the conclusion that this particular age may be ideal for the inculcation and establishment of healthy weight management behaviour, which will continue into late adulthood. This, in turn will be a preventive measure against lifestyle based diseases.

\section{Funding: ICMR STS Project}

Conflict of interest: None declared

Ethical approval: The study was approved by the Institutional Ethics Committee

\section{REFERENCES}

1. Chatterjee V. India sees parallel rise in malnutrition and obesity. Lancet. 2002;360(9349):1948.

2. Brener ND, Eaton DK, Lowry R, McManus T. The association between weight perception and BMI among high school students. Obes Res. 2004;12(11):1866-74.

3. Strauss RS. Self- reported weight status and dieting in a cross- sectional sample of young adolescents: national health and nutrition examination survey. Arch Pediatr Adolesc Med. 1999;153(7):741-7.

4. Sirang Z, Bashir HH, Jalil B, Khan SH, Hussain SA, Baig A, Taufeeq M, Samad K, Kadir MM. Weight patterns and perceptions among female university students of Karachi :a cross sectional study. BMC Pub health. 2013;13(230).

5. Cheung PCH, Ip PLS, Lam ST, Bibby H. A study on body weight perception and weight control behaviours among adolescents in Hong Kong. Hong Kong Med J. 2007;13:16-21.

6. Chang VW, Christakis NA. Self-perception of weight appropriateness in the United States. Am J Prev Med. 2003;24(4):332-9.

7. Priya D, Prasanna KS, Sucharitha S, Vaz NC. Body image perception and attempts to change weight among female medical students at Mangalore. Ind J Community Med. 2010;35(2):316-20.

8. WHO expert consultation. Appropriate body-mass index for asian populations and its implications for policy and intervention strategies. Lancet. 2004; 363:157-63.

9. Wang Y, Liang H, Chen X. Measured body mass index, body weight perception, dissatisfaction and control practices in urban, low-income African American adolescents. BMC Pub Health. 2009;9:183.
10. Foneseca H, de Matos MG. Perception of overweight and obesity among portuguese adolescents: an overview of associated factors. Eur J Pub Health. 2005;15(3):323-8

11. Misra A, Chowbey P, Makkar BM, Vikram NK, Wasir JS, Chadha D et al. Consensus statement for diagnosis of obesity, abdominal obesity and the metabolic syndrome for asian indians and recommendations for physical activity, medical and surgical management. J Assoc Physicians India. 2009;57:163-70.

12. Gopalakrishnan S, Ganeshkumar P, Prakash MVS, Christopher, Amalraj V. Prevalence of overweight / obesity among the medical students, Malaysia. Med J Malaysia. 2012;67(4):442-4.

13. Rao CR, Darshan BB, das N, Rjan V, Bhogun M, Gupta A. Practice of physical activity among future doctors: a cross sectional analysis. Int J Prev Med. 2012;3(5):365-69.

14. Bhadra M, Mukhopadhyay A, Bose K. Adiposity, central body fat distribution and blood pressure amongyoung bengalee adults of kolkata, India: sexual dimorphism. J Physiol Anthropol. 2002;21 (6):273-6.

15. Thakkar HK. Obesity and weight control measures: findings from female college students of agra. Med J DY Patil Univ. 2013;6(1):66-70.

16. Singhal N, Misra A, Shah P, Rastogi K, Vikram NK. Secular trends in obesity, regional adiposity and metabolic parameters among Asian Indian adolescents in North India: a comparative data analysis of two selective samples 5 years apart. Ann Nutr Metab. 2010;56:176-81.

17. Yadav K, Krishnan A. Changing patterns of diet, physical activity and obesity among urban, rural and slum populations in north India. Obes Rev. 2008;9(5):400-8.

18. Gross SM, Scott-Johnson PE, Browne DC. Collegeage, African-American males misperceptions about weight status, body size, and shape. Ethn Dis. 2005;15(4 Suppl 5):S5-34-8.

19. Wronka I, Suliga E, Pawlińska-Chmara R. Perceived and desired body weight among female university students in relation to BMI-based weight status and socio-economic factors. Ann Agric Environ Med. 2013;20(3):533-8.

20. Abalkhail B, Shawky S, Ghabrah T. Perception of body weight among Saudi school children. J Family Community Med. 2002;9(3):35-49.

Cite this article as: Saiprasanna N, Ilavenil K, Sasikumar S, Subashini K, Nalinakumari SD. Body mass index status and accuracy of individual weight status perception among college going students in South India. Int J Community Med Public Health 2016;3:1559-63. 